\title{
Preoperative Upper Gastrointestinal Testing Can Help Predicting Long-term Outcome After Gastric Banding for Morbid Obesity
}

\author{
Michel Suter • Vittorio Giusti • Jean-Marie Calmes • \\ Alexandre Paroz
}

Published online: 18 March 2008

(C) Springer Science + Business Media B.V. 2007

\begin{abstract}
Background Gastric banding (GB) is one of the most popular bariatric procedures for morbid obesity. Apart from causing weight loss by alimentary restriction, it can interfere with functions of the esophagus and upper stomach. The aim of this study was to evaluate if the results of extensive preoperative upper GI testing were correlated with long-term outcome and complications after GB.

Methods Using a prospectively maintained computerized database including all the patients undergoing bariatric operations in both our hospitals, we performed a retrospective analysis of the patients who underwent complete upper gastrointestinal (GI) testing (endoscopy, $\mathrm{pH}$ monitoring, and manomatry) before GB.

Results One hundred thirty-four patients underwent complete testing before GB. Abnormal $\mathrm{pH}$ monitoring (increased total reflux time, increased diurnal reflux time, increased number of reflux episodes) predicted the development of complications and especially pouch dilatation and food intolerance. The mean De Meester score was higher among patients who developed complications than
\end{abstract}

Presented at the 12th World Congress of the International Federation for the Surgery of Obesity, Porto, Portugal, September 6, 2007.

M. Suter $(\square)$

Department of Surgery, Hôpital du Chablais, Aigle-Monthey, 1860 Aigle, Switzerland

e-mail: michelsuter@netplus.ch

V. Giusti

Division of Endocrinology, Diabetology and Metabolism,

Centre Hospitalier Universitaire Vaudois (CHUV),

Lausanne, Switzerland

M. Suter · J.-M. Calmes $\cdot$ A. Paroz

Department of Visceral Surgery, Centre Hospitalier Universitaire

Vaudois (CHUV), Lausanne, Switzerland in the remaining ones ( 25.4 vs $17.7, P=0.03$ ). High lower esophageal sphincter pressure also predicted progressive long-term food intolerance. Endoscopic findings were not predictive of the long-term outcome.

Conclusions There is some association between the function of the upper digestive tract and long-term complications after gastric banding. Abnormal $\mathrm{pH}$ monitoring predicts overall long-term complications, especially food intolerance with or without reflux, and pouch dilatation, and a high lower esophageal sphincter pressure predicts long-term food intolerance. Extended upper gastrointestinal testing with endoscopy, 24-h $\mathrm{pH}$ monitoring, and esophageal manometry is probably worthwhile in selecting patients for gastric banding.

Keywords Morbid obesity · Gastric banding - Manometry . $\mathrm{pH}$-monitoring · Gastroesophageal reflux disease .

Complications

\section{Introduction}

The prevalence of overweight and obesity has increased markedly in the western world during the past three decades. Obesity significantly reduces quality of life, is responsible for a large number of comorbid medical conditions, and reduces life expectancy. Despite the refinements of diet therapy and the recent development of new drugs, bariatric surgery is still the only means to provide patients with effective and durable weight loss. The important weight reduction that follows bariatric procedures has been shown to not only increase quality of life but also to improve or reverse comorbidities and reduce obesityrelated mortality especially from cardiovascular disease and cancer [1-5]. 
Laparoscopic gastric banding, being the first minimally invasive approach to morbid obesity, was soon adopted as a very safe, simple, and reversible bariatric procedure by many surgeons especially in Europe, Australia, and Latin America, with early results in terms of weight loss comparable to those of other restrictive operations. With time, however, it became apparent that in the long term, a significant number of patients do not achieve sufficient weight loss or develop complications that jeopardize the overall results of the procedure [6]. So far, very little is known about the reasons why some patients develop complications and others do not. Patient's compliance, and especially eating behavior, has been blamed among others, and large hiatus hernias have traditionally been considered as a contraindication for gastric banding (GB) by most surgeons. Morbidly obese patients are known to have a high prevalence of gastroesophageal reflux disease (GERD) and esophageal motility disorders. In a cohort of 345 morbidly obese patients awaiting bariatric surgery, we found a hiatus hernia in 52.6\%, reflux esophagitis in 31.4\%, and an elevated De Meester score at 24-h pH monitoring in $51.7 \%$ of the patients. In the same group, manometry was altered in $25.6 \%$ of the patients [7]. GB has been shown to have various effects on reflux. It can act as an antireflux procedure or it can enhance GERD [8-13]. GB also rapidly alters esophageal motility, with a decrease in the amplitude of contractions in the lower esophagus as soon as 9 months after surgery [13]. Whether the preoperative functional status of the esophagus and gastroesophageal junction plays a role in the long-term results of gastric banding, and especially in the development of complications, is largely unknown. So far, a single study by Lew et al. [14] has evaluated the relationship between preoperative manometry, weight loss, vomiting, and the diameter of the esophagus during the first two postoperative years. In a group of 77 patients, these authors found no correlation between manometry and weight loss or the esophageal diameter, but more severe vomiting in patients with an abnormal manometry. The aim of the present study was to evaluate, in a larger group of morbidly obese patients submitted to gastric banding and followed up for a long period of time, whether long-term outcome of gastric banding with respect to weight loss or the development of long-term complications could be predicted by the results of extended upper gastrointestinal testing with endoscopy, 24-h $\mathrm{pH}$ monitoring, and manometry.

\section{Patients and Methods}

In our two institutions, a multidisciplinary team evaluated all morbidly obese patients presenting for bariatric surgery. Between January 1999 and April 2003, once indication for surgery was confirmed according to the consensus development conference panel of the National Institute of Health and to the consensus on obesity treatment in Switzerland $[15,16]$ and contraindications were excluded, patients were evaluated for digestive symptoms and underwent complete upper gastrointestinal objective testing with endoscopy, 24-h pH monitoring, and stationary esophageal manometry. Esophagogastroduodenoscopy was performed using a standard gastrofibroscope. A hiatus hernia was diagnosed if the distance between the Z-line and the hiatus opening was more than $1 \mathrm{~cm}$. Esophagitis was graded according to the modified Savary-Miller classification [17]. Esophageal manometry testing was performed using perfused eight-lumen catheters SE-25381_4+4 (Sedia, Givisiez, Switzerland). Esophageal body function was assessed with the four proximal pressure transducers. The distance between the transducers was $5 \mathrm{~cm}$. The function of the lower esophageal sphincter (LES) was assessed by four pressure transducers placed at the same level, one in each quadrant. During the procedure, the patients performed ten wet and ten dry swallows. Manometry data were analyzed with the Sedia NT Oes software (Sedia). Twenty-four hours $\mathrm{pH}$ monitoring was performed with the glass electrodes F8-IR (Simtec, Basel, Switzerland). The distal tip of the probe was placed $5 \mathrm{~cm}$ above the gastroesophageal junction. The patient was monitored for $24 \mathrm{~h}$, and $\mathrm{pH}$ data were recorded on a data logger Gastrograph (new name $\mathrm{pH}$-graph, Simtec) downloaded onto a PC and analyzed with the MIC Gastro V1.7 software (MIC, Solothurn, Switzerland).

The LES pressure was considered normal between 10 and $45 \mathrm{mmHg}$. Incomplete relaxation of the LES was defined as a less than $70 \%$ relaxation only. Nutcracker esophagus was diagnosed if the mean contraction amplitude was above $180 \mathrm{mmHg}$ in the lower esophagus. Nonspecific motility disorders were defined as either amplitude of the contraction wave below $30 \mathrm{mmHg}$ in the lower esophagus and/or as the existence of more than $30 \%$ nonperistaltic contractions. The results of $\mathrm{pH}$ monitoring were considered abnormal with a De Meester score $>14.7$. In our laboratory, the cutoff values for the results of $\mathrm{pH}$-metry were as follows: $4.7 \%$ for the total reflux time, $8.3 \%$ for daily reflux, $3.3 \%$ for nocturnal reflux, 50 for the total number of reflux episodes, 4 for the number of prolonged reflux episodes, and $20 \mathrm{~min}$ for the longest reflux duration.

Gastric banding was the only bariatric procedure offered at the beginning of this study. Roux-en-Y gastric bypass was slowly introduced since June 1999 and first offered mostly to superobese patients before being proposed to all patients. The choice of procedure was then made together with the patient after complete information and a long discussion regarding pros and cons. All the operations were performed laparoscopically under general anesthesia. The operative technique used for GB has been described elsewhere [18]. 
Table 1 Long-term complications

\begin{tabular}{lcc}
\hline Type of complication & Number & Percentage \\
\hline Pouch dilatation with or without slippage & 9 & 6.7 \\
Esophageal dilatation & 12 & 8.9 \\
Severe food intolerance with or without & 8 & 5.9 \\
$\quad$ reflux & 16 & \\
Band erosion & 3 & 11.9 \\
Others & 44 & 32.8 \\
Total patients with major complications & & \\
\hline
\end{tabular}

Briefly, the Lapband ${ }^{\circledR}$ (Bioenterics, Carpinteria, CA, USA) was placed using the perigastric technique, and the $\mathrm{SAGB}^{\circledR}$ (Obtech medical for Ethicon Endosurgery, $6310 \mathrm{Zug}$, Switzerland) was placed according to the pars flaccida technique. All the patients included in this series were part of a randomized prospective trial, which intended to compare the results between these two bands [19]. A large hiatus hernia $(>2 \mathrm{~cm})$ was considered as a contraindication to GB.

Both the surgical and medical team followed patients. All patients' data were entered prospectively in a computerized database. In a retrospective analysis, weight loss and complications in patients who underwent gastric banding were evaluated according to the results of preoperative upper gastrointestinal tests.

Major long-term complications were defined as pouch dilatation with or without band slippage, severe food intolerance \pm symptomatic reflux, esophageal dilatation, band erosion, and any other complication leading to band removal such as band leak. Failure was considered in patients in whom the band had to be removed or in those who failed to achieve an excess weight loss of at least $25 \%$.

Statistical analysis was performed using the Student's $t$ test for numerical variables and with the chi-square or exact Fisher's test for categorical variables as appropriate. Statistical significance was accepted at a $p$ level $<0.05$.

\section{Results}

Complete datasets were available for a total of 134 patients, 113 women and 21 men, with a mean age of 38 years
(21-64). The mean preoperative body mass index (BMI) was $42.7 \mathrm{~kg} / \mathrm{m}^{2}$ (34.3-53.2). Sixty-six patients had a small $(<2 \mathrm{~cm})$ hiatus hernia, and $71(53.8 \%)$ had GERD as proven by the presence of esophagitis at preoperative endoscopy and/or a pathologic preoperative De Meester score at 24-h pH-metry. Twenty-five (18.9\%) patients had a pathologic esophageal manometry, the most common finding being a low LES pressure. These figures correspond roughly to what we found in a large group of morbidly obese patients scheduled for bariatric surgery [12]. Gastric banding was done with a Lapband ${ }^{\circledR}$ in 64 , and a SAGB ${ }^{\circledR}$ in 70 patients. Duration of follow-up was between 51 and 106 months (mean 85). The mean\% of excess BMI loss for patients who retained the band was $65.2,64.3$, and 64.1 after 3,5 , and 7 years, respectively. A total of 44 patients $(32.8 \%)$ developed at least one major long-term complication (Table 1), of which $38(28.3 \%)$ so far required band removal with or without conversion to another bariatric procedure. Because of insufficient weight loss or band removal, 54 patients $(40.3 \%)$ were considered as failures.

We could not find any relationship between the results of any preoperative digestive tests and weight loss or the overall failure rate. Contrary to what we expected, the results of endoscopy, and especially the presence of a hiatus hernia or esophagitis, were not predictive of any type of complication. There was, however, a relationship between the results of 24-h $\mathrm{pH}$ monitoring and the overall complication rate. The mean De Meester score was higher (25.4 vs $17.7, p=0.03$ ) in patients who developed complications. More specifically, complications were more common in patients with an elevated daily reflux time (47.2 vs $24.4 \%, p=0.02$ ), and there was a trend for more complications in patients with an increased total reflux time (41.7 vs $26 \%, p=0.07$ ).

Considering specific complications, the mean preoperative LES pressure was higher ( 24 vs $17.3 \mathrm{~cm} \mathrm{H}_{2} \mathrm{O}, p=0.05$ ) in patients who developed severe late food intolerance and/ or reflux. The latter were also more common in patients with long reflux episodes ( 3 vs $14.3 \%, p=0.05$ ) than in those without this finding at $24-\mathrm{h} \mathrm{pH}$ monitoring. Pouch dilatation with or without slippage was more common in patients who received a Lapband ${ }^{\circledR}$ than in those with a $\mathrm{SAGB}^{\circledR}$. This complication was clearly related to findings
Table 2 Relationship between findings of 24-h $\mathrm{pH}$ monitoring and the occurrence of late pouch dilatation with or without slippage

\begin{tabular}{lccc}
\hline & \multicolumn{2}{c}{$\%$ Patients with pouch dilatation with or without slippage } & $p$ value \\
\cline { 2 - 3 } & Normal & Elevated & \\
\hline De Meester score & 1.7 & 13.4 & 0.03 \\
\% Total reflux time & 1,3 & 17.1 & 0.005 \\
\% Daily reflux time & 1.2 & 24.1 & $<0.001$ \\
Number of long reflux episodes & 3.2 & 20.8 & 0.01 \\
\hline
\end{tabular}


at $\mathrm{pH}$ monitoring (Table 2) and was more frequent in patients with abnormal findings. We could not demonstrate any correlation between preoperative tests and late esophageal dilatation, especially regarding results of preoperative manometry, nor did we find any relationship between late band erosion/migration and preoperative tests.

\section{Discussion}

Laparoscopic gastric banding is considered the safest bariatric procedure, with a low operative morbidity, and mortality usually below $0.1 \%$. In the majority of operated patients, GB produces effective weight loss because of food restriction, with variable degrees of food intolerance and vomiting. Satisfactory weight loss, in the early postoperative years, is obtained in approximately two thirds of patients [20]. With increasing length of follow-up, however, a growing number of long-term complications arise, such as pouch dilatation with or without slippage, band erosion, progressive esophageal dilatation with pseudoachalasia, food intolerance with gastroesophageal reflux, band leaks. These complications are sometimes difficult to manage and often lead to progressive weight regain. Reasons why some patients tolerate the band very well and others develop complications are essentially unknown, although eating behavior, which shows abnormal patterns in the majority of morbidly obese patients, and preexisting conditions of the upper gastrointestinal tract like hiatus hernia, GERD, and esophageal motility disorders have been incriminated. It would be of interest to be able to better select morbidly obese patients for gastric banding and exclude from this procedure those in whom long-term complications can be anticipated on the basis of preoperative factors.

In the present study, the first of this type to the best of our knowledge, we confronted the results of extended upper gastroesophageal testing with long-term results of gastric banding in 134 fully investigated patients. The results of preoperative endoscopy did not correlate with long-term morbidity, but some correlations were found between the results of 24-h $\mathrm{pH}$ monitoring or esophageal manometry and complications. Patients who developed any type of long-term complications tended to have a higher De Meester, although the mean score in both groups were abnormally elevated. More reflux was especially associated with late pouch dilatation with or without band slippage. The latter complication was also more common in patients operated with a Lapband ${ }^{\circledR}$ than in those with a SAGB ${ }^{\circledR}$. This is most probably related to the operative technique. The Lapband ${ }^{\circledR}$ were placed using the perigastric technique and the SAGB ${ }^{\circledR}$ using the pars flaccida technique, and it has been shown that the latter reduces the frequency of pouch dilatation [21]. Long reflux episodes were associated with poor late food tolerance, and patients who developed this complication also had a higher preoperative LES pressure than those who did not. As has been recognized, reflux in morbidly obese patients is mostly caused by transient LES relaxation [22]. It may be that in these patients, a high resting LES disturbs esophageal clearance between reflux episodes, thereby increasing esophageal exposure to acid and residual food.

Others have studied the relationship between preoperative esophageal manometry and outcome after laparoscopic gastric banding [19]. Like us, they found no correlation between the results of this test and early weight loss, but they noticed more severe vomiting in patients with abnormal manometry. This is partly in accordance with our results. Duration of follow-up, however, was limited in the latter study, so that late effects of preoperative manometry results could not be assessed. We are not aware of any published study in which the results of preoperative $24-\mathrm{h} \mathrm{pH}$ monitoring were confronted with long term outcome of gastric banding.

\section{Conclusions}

On the basis of our results, we believe that there is some association between the function of the upper digestive tract and long-term complications after gastric banding. Abnormal $\mathrm{pH}$ monitoring predicts overall long-term complications, especially food intolerance with or without reflux and pouch dilatation, and a high LES pressure predicts longterm food intolerance. Extended upper gastrointestinal testing with endoscopy, 24-h pH monitoring, and esophageal manometry is probably worthwhile in selecting patients for gastric banding. Confronting complete preoperative evaluation with long-term outcome in a much larger group of patients would probably help to better understand the precise relationship that may exist and the mechanisms by which complications develop.

\section{References}

1. Buchwald H, Avidor Y, Braunwald E, Jensen MD, Pories W, Fahrbach K, et al. Bariatric surgery. A systematic review and meta-analysis. JAMA 2004;292:1724-37.

2. Christou NV, Sampalis JS, Liberman M, et al. Surgery decreases long-term mortality, morbidity and health care use in morbidly obese patients. Ann Surg 2004;240:416-24.

3. Flum DR, Dellinger EP. Impact of gastric bypass operation on survival. A population-based analysis. J Am Coll Surg 2004;199:543-55.

4. Adams TD, Gress RE, Smith SC, et al. Long-term mortality after gastric bypass surgery. N Engl J Med 2007;357:753-61.

5. Sjöström L, Narbro K, Sjöström CD, et al. Effects of bariatric surgery on mortality in Swedish obese subjects. N Engl J Med 2007;357:741-52. 
6. Suter M, Calmes JM, Paroz A, Giusti V. A ten-year experience with laparoscopic gastric banding: high long-term complication and failure rates. Obes Surg 2006;16:829-35.

7. Suter M, Dorta G, Giusti V, Calmes JM. Gastroesophageal reflux and esophageal motility disorders in morbidly obese patients. Obes Surg 2004;14:959-66.

8. Weiss HG, Nehoda H, Labeck B, Peer-Kühberger R, Klingler P, Gadenstätter $\mathrm{M}$, et al. Treatment of morbid obesity with laparoscopic adjustable gastric banding affects esophageal motility. Am J Surg 2000;180:479-82.

9. Iovino P, Angrisani L, Tremolaterra F, Nirchio E, Ciannella M, Borrelli V, et al. Abnormal esophageal acid exposure is common in morbidly obese patients, and improves after successful LapBand system implantation. Surg Endsoc 2002;16:1631-5.

10. Øvrebø KK, Hatlebakk JG, Viste A, Bassøe HH, Svanes K. Gastroesophageal reflux in morbidly obese patients treated with gastric banding or vertical banded gastroplasty. Ann Surg 1998;228:51-8.

11. Peternac D, Hauser R, Weber M, Schöb O. The effects of laparoscopic adjustable gastric banding on the proximal pouch and the esophagus. Obes Surg 2001;11:76-86.

12. De Jong JR, van Ramshorst B, Timmer R, Gooszen HG, Smout AJPM. The influence of laparoscopic adjustable gastric banding on gastroesophageal reflux. Obes Surg 2004;14:399-406.

13. Suter M, Dorta G, Giusti V, Calmes JM. Gastric banding interferes with esophageal motility and gastroesophageal reflux. Arch Surg 2005;140:639-43.
14. Lew JI, Daud A, DiGorgi MF, et al. Preoperative esophageal manometry and outcome of laparoscopic adjustable gastric banding. Surg Endosc 2006;20:2142-7.

15. Consensus Development Conference Panel. Gastrointestinal surgery for severe obesity: consensus development conference statement. Ann Intern Med 1991;115:956-61.

16. Consensus sur le traitement de l'obésité en Suisse. Schweiz Med Wochenschr 1999;129 Suppl 114:4S-20S.

17. Ollyo JB, Lang F, Fontoillet C, Monnier P. Savary-Miller's new classification of reflux esophagitis: a simple, reproducible, logical, complete and useful classification. Gastroenterology 1990;98: A100.

18. Suter M, Bettschart V, Giusti V, et al. A 3-year experience with laparoscopic gastric banding for obesity. Surg Endosc 2000;14:532-6.

19. Suter M, Giusti V, Worreth M, et al. Laparoscopic gastric banding. A prospective study comparing the Lapband and the SAGB: early results. Ann Surg 2005;241:55-62.

20. Suter M, Giusti V, Héraief E, et al. Laparoscopic gastric banding. Beyond the learning curve. Surg Endosc 2003;17:1418-25.

21. O'Brien PE, Dixon JB, Laurie C, Anderson M. A prospective randomized trial of placement of the laparoscopic adjustable gastric band: comparison of the perigastric and pars flaccida pathways. Obes Surg 2005;15:820-6.

22. Dent J, Holloway RH, Toouli J, Dodds WJ. Mechanisms of lower oesophageal sphincter incompetence in patients with symptomatic gastroesophageal reflux. Gut 1998;29:1020-8. 